\title{
LAS TENSIONES ENTRE TÉCNICA Y PROYECTO DE VIDA EN LA MEDITACIÓN DE LA TÉCNICA \\ DE ORTEGA Y GASSET
}

\author{
THE TENSIONS BETWEEN TECHNIQUE \\ AND LIFE PROJECT IN ORTEGA Y GASSET'S \\ MEDITACIÓN DE LA TÉCNICA
}

\author{
Marcos Alonso FernándeZ* \\ Universidad Autónoma de Madrid
}

\begin{abstract}
Resumen: El presente artículo trata de exponer las relaciones que Ortega y Gasset establece entre proyecto de vida y técnica. La articulación entre estas dos instancias, decisiva para la comprensión de la metafísica de la vida humana del filósofo español, se revelará como un tema complicado y cambiante dentro de la producción orteguiana. Mediante esta discusión se propondrá asimismo una nueva comprensión de las relaciones entre teoría y práctica, otro de los temas orteguianos por excelencia.
\end{abstract}

Palabras ClaVe: técnica, proyecto de vida, metafísica, antropología, Ortega.

Aвstract: The present paper attempts to expose the relations Ortega y Gasset establishes between life project and technique. The articulation between these two instances, decisive for the comprehension of the Spanish philosopher's metaphysics of human life, will be revealed as a complex and changing theme in Ortega's works. Through this discussion we will also propose a new comprehension of the relationships between theory and praxis, another Orteguian theme par excellence.

KEYwORDs: technique, life project, human life, metaphysics, anthropology, Ortega.

* Marcos Alonso Fernández es ayudante post-doctoral en la Universidad Autónoma de Madrid (Ciudad Universitaria de Cantoblanco, 28049 Madrid). Email: marcs.alonso@gmail. 


\section{Introducción: la técnica subordinada al proyecto de vida}

En este artículo trataremos de aclarar uno de los puntos más importantes de la metafísica de la vida humana de Ortega: el sentido e importancia de su noción de proyecto en relación con su comprensión de la técnica. Como veremos, no se puede decir que la propuesta orteguiana carezca de problemas, pero desde el principio hay que reconocer el mérito de Ortega al tratar de establecer una conexión entre ambas dimensiones, su intento de articular el proyecto de vida que caracteriza a la vida humana, con la técnica que lo hace posible y que sostiene dicha vida. Ante este problema la argumentación orteguiana experimentará numerosos altibajos y dificultades, alternando destellos de lucidez con recaídas en la postura más habitual dentro de la tradición filosófica, en la cual al proyecto de vida se le da un peso mucho mayor que a la técnica, sostén material de esa vida humana. Al hilo de esta concreta discusión podremos también ver cómo el filósofo español elabora su particular concepción de las relaciones entre teoría y práctica, tema nuclear y recurrente de la tradición filosófica.

Una de las exposiciones más claras de esta tensión del planteamiento orteguiano la encontramos en Meditación de la técnica. En este decisivo texto, después de remarcar la importancia superlativa de la técnica y su indisoluble imbricación con la vida humana, Ortega acaba, no obstante, afirmando que es el proyecto de vida que somos o ideal de vida buena al que en cada época aspiramos, lo que rige verdaderamente a la técnica: "Y sin embargo, o por lo mismo, la técnica no es en rigor lo primero. [...] ella por sí no define el programa, quiero decir que a la técnica le es prefijada la finalidad que ella debe conseguir. El programa vital es pre-técnico" (V 575) ${ }^{1}$. Esta idea ha sido asumida de manera generalizada por muchos intérpretes. Por ejemplo Diéguez y Zamora afirman que "la técnica, sin embargo, como bien vio Ortega, no puede definir el programa vital de nadie. Ella no es un fin. En ese sentido, está vacía" (Diéguez y Zamora, 2015, p. 35). En un sentido muy similar se expresan otros autores como Dust (cf. 1993, p. 127), Esquirol (cf. 2011, pp. 29-30) o Cerezo (cf. 1984, p. 189). Pese al relativo consenso respecto de este punto, este artículo defenderá la necesidad de problematizar este punto, una defensa que se llevará a cabo en la última parte de este texto. Antes de realizar esta anunciada problematización, conviene, no obstante, dejar asentado

\footnotetext{
${ }^{1}$ Para las obras de Ortega citaremos haciendo referencia al tomo de las obras completas (Ortega y Gasset, José (2004-2010). Obras completas. Tomos I-X. Madrid: Taurus) en numeración latina seguido del número de página correspondiente.
} 
este punto de la argumentación orteguiana, esta primera postura en la que defenderá de manera clara la primacía del proyecto sobre la técnica.

En el mismo texto de Meditación de la técnica, unas pocas líneas después al texto antes referido, Ortega prosigue afirmando que la técnica, al consistir en el cumplimiento de las necesidades superfluas que el programa de vida humana le pide, está subordinada a este programa de vida; el cual, dirá Ortega al final del párrafo, es "la invención por excelencia, que es el deseo original" (V 575). Este "deseo propiamente creador, el que postula lo inexistente, el que anticipa lo que aún es irreal” (V 576), es mucho más difícil de llevar a cabo de lo que solemos creer, pues supone una novedad radical, un verdadero inicio. El diagnóstico socio-histórico de Ortega, enunciado ya en La rebelión de las masas y en España invertebrada, es precisamente ese: "Acaso la enfermedad básica de nuestro tiempo sea una crisis de los deseos, y por eso toda la fabulosa potencialidad de nuestra técnica parece como si no nos sirviera de nada" (V 576).

Los siguientes capítulos de Meditación de la técnica se propondrán precisamente ejemplificar esta idea con algunos ejemplos históricos, principalmente con el caso de la técnica moderna y el ideal de vida del gentleman. La tesis básica de Ortega es que el gentleman es un ideal de hombre para el que el bienestar físico y material es sumamente importante, lo que precisamente da lugar a todas las técnicas modernas eminentemente físicas y centradas en la mejora de las condiciones materiales: "Un hombre de módulo muy intelectual no hubiera nunca ideado el water-closet, porque despreciaba su cuerpo. El gentleman, repito, no es intelectual. Busca el decorum en toda su vida: alma limpia y cuerpo limpio" (V 584). En un mismo sentido, dirá Ortega que el gentleman sólo puede aparecer cuando hay riqueza y exceso económico (cf. V 584), pues sin éstos su tipo de vida se hace imposible: "la atmósfera del ser gentleman reside en una sensación básica de holgura vital, de dominio superabundante sobre la circunstancia. Si ésta ahoga, no es posible educarse hacia la gentlemanerie" (V 583). El gentleman, concluirá Ortega, se preocupa mucho de dominar su hostil circunstancia, "de ahí que haya sido el gran técnico y el gran político” (V 583). Si bien Ortega en estas líneas está poniendo en juego algunos hallazgos realmente valiosos, también está al mismo tiempo asumiendo y reproduciendo un prejuicio inveterado sobre la técnica. Un prejuicio, y esto es lo más sorprendente, que el propio Ortega parece comprender y criticar en otros momentos de su obra.

Pues desde las propias categorías orteguianas se nos hace necesario realizar la siguiente pregunta: ¿Es realmente la técnica moderna el resultado del «ideal de vida gentleman»? ¿O es el gentleman un tipo de vida que sólo fue posible -y no sólo posible en un sentido material, sino posible en el sentido de imaginable- 
a raíz de la técnica moderna que trajo innumerables avances materiales? Quizás la solución no sea ninguna de estas dos tesis; no, al menos, de manera independiente, suponiendo que afirmar una implique negar la otra. En otro momento de Meditación de la técnica podemos ver este mismo problema desde un ejemplo contrapuesto al del gentleman. Allí Ortega defiende la preponderancia del proyecto vital sobre la técnica con el ejemplo del ideal de vida bodhisatva, que se caracteriza, en oposición al gentleman, por despreciar lo material y centrarse en lo espiritual. A este respecto, Ortega anticipa la crítica que fácilmente podría hacérsele:

... la explicación naturalista de lo humano saltará aquí sosteniendo que la relación entre proyecto de ser y la técnica es inversa de la que yo propongo, a saber: que es el proyecto quien suscita la técnica, la cual, a su vez, reforma la naturaleza. Todo lo contrario, se dirá: en la India el clima y el suelo facilitan $\tan$ enormemente la vida que el hombre apenas necesita moverse ni alimentarse. Es, pues, el clima y el suelo quienes preforman ese tipo de vida pública. (V 579-580)

Sin embargo, dirá Ortega, "si son el clima y la tierra de la India quienes explican el budismo de la India, no se comprende por qué la región budista por excelencia es el Tibet" (V 580), "uno de los lugares más ásperos y crudos del planeta" (V 58). Antes de continuar habría que hacer una puntualización fundamental. Pues, desde las categorías orteguianas ni siquiera tiene sentido hablar de aspereza y crudeza en sentido absoluto, sino en relación a una determinada forma de vida. Para algunas formas de vida, las bajas temperaturas no serían un problema, sino la condición básica para su vida. Ortega, como desafortunadamente sucede en otras ocasiones, no mantiene el pulso de su mejor filosofía, cayendo en posturas más simples o directamente confusas.

\section{Problematizaciones de las relaciones entre la técnica y el pro- yecto de vida}

No obstante, si seguimos con el razonamiento de Ortega llegaremos al punto fundamental que aquí queríamos discutir. Lo que Ortega quiere hacer notar con el ejemplo antes comentado es que la vida bodhisatva de desapego material resulta en cierto modo contradictoria con las condiciones exigentes del Tibet; lo cual sólo puede explicarse por la casualidad de que los templos que esta forma de vida bodhisatva construyó para meditar acabaron desempeñando una función 
distinta de refugio militar. Pero como antes apuntaba, todo esto a lo sumo sólo demostraría que el proyecto puede imponerse sobre la circunstancia, incluso en los casos en que ésta es máximamente opuesta a dicho proyecto vital. Pero en esta argumentación no se atisba en qué sentido podría ser el proyecto anterior a la técnica. ¿Cómo puede siquiera entenderse el proyecto o programa vital como algo pre-técnico?

Los propios ejemplos de Ortega se vuelven contra su tesis. Pues, ¿cómo hubiera podido siquiera proyectarse el ideal de vida gentleman sin las técnicas de cuidado del cuerpo que surgieron alrededor del siglo XIX? ¿Cómo podría nadie plantearse ser bodhisatva sin la técnica que son sus templos? Con esto no quiero decir que la técnica sea previa, y me parece que Ortega acierta en criticar esta postura de preeminencia de la técnica. Pero de esta negativa no se puede deducir la afirmación de su contrario, de que el proyecto es lo primero. Sobre este punto creo que debemos aspirar a una postura más compleja, una postura que entienda al proyecto y a la técnica como dimensiones inseparables, como co-principios siempre conjugados y co-implicados.

Algunos intérpretes ya han localizado este error de la argumentación orteguiana, poniendo de manifiesto cómo esta tesis va en contra de sus propios postulados. Conviene recordar las acertadas palabras de J. L. González Quirós al respecto:

El Ortega de verano del 33 oscila entre dos ideas distintas acerca del significado y la importancia de la técnica. Por una parte, la idea con la que ha comenzado sus intervenciones, la afirmación radical de que "sin la técnica el hombre no existiría ni habría existido nunca”. Y por otra, la idea, bastante más convencional, del carácter artificioso de la técnica, de que la técnica pudiera considerarse incluso como un matarife del deseo, de la facultad de desear, justamente la lectura que algunos han subrayado como característicamente orteguiana (2013, p. 101)

González Quirós explica asimismo que al final de la argumentación "Ortega vuelve de nuevo a un cierto sentido común para advertir que, en cualquier caso, el programa vital es pre-técnico, lo que no es sino reconocer de nuevo la ambigüedad de su posición" (2013, p. 107). I. Quintanilla reprocha también a Ortega que no profundice en este punto decisivo, pues según este autor, Ortega "apela inmediatamente a una supeditación de la técnica a los fines últimos de la vida humana y al discurso que se los plantea. Ahora bien, es justo la relación entre la técnica y las cuestiones últimas la que está por explorar" (Quintanilla, 
1999, p. 187), es decir, que eso que Ortega da por supuesto sin justificar es precisamente lo que no puede asumirse tan apresuradamente, siendo como es el asunto verdaderamente grave y decisivo.

I. Ellacuría ha sido uno de los intérpretes que mejor ha visto esta tensión del planteamiento orteguiano, una tensión que se refleja en la pregunta de si "¿es el proyecto el que condiciona las posibilidades, las capacidades con que cuento para realizarlo, o son las capacidades efectivas con que cuento las que delimitan cuál es mi auténtico proyecto?” (Ellacuría, 1996, p. 491); pregunta a la cual Ellacuría responde que "Ortega no cuenta con una solución clara para fundamentar esta segunda prioridad fundamental [la de los fines proyectados], a la cual, sin embargo, en muchos pasajes se adscribe" (Ellacuría, 1996, p. 491). Como el propio Ellacuría acaba concluyendo,

Ciertamente que es preciso reconocer un condicionamiento mutuo, ya que sólo el proyecto pone en movimiento esas capacidades efectivas dadas, mientras que, por otra parte, sólo estas capacidades efectivas son las que posibilitan la realización del proyecto. El problema, con todo, no queda plenamente resuelto, porque si se puede hablar de una prioridad del proyecto en cuanto tal, respecto de las capacidades dadas en la medida que las mueve en su ejercicio - sin que esto obste a una posteridad en cuanto proyecto realizado-, queda todavía el gran interrogante de por qué ese proyecto es mío. (1996, pp. 491-492)

Ellacuría pone el dedo en la llaga al preguntar "¿Quién humaniza y ensimisma a quién: la vida al yo parcial o el yo parcial a la vida?” (1996, p. 492). La única salida posible parece residir en establecer una cierta continuidad no reduccionista entre el ente que soporta la vida humana y la efectiva vida humana a la que da lugar ese ente. Esta conclusión es muy cercana a la de Ellacuría, quien afirma que "esto hace recobrar importancia al ente que con su entidad y sus mecanismos psíquicos determina en parte la consistencia del proyecto, que, a su vez, reobrará sobre la vida entera y, a través de ella, sobre el ente que es el hombre y el ente que es el mundo" (Ellacuría, 1996, p. 474).

Por último también cabría citar a este respecto a L. Espinosa, otro de los estudiosos de la filosofía de la técnica orteguiana que mejor ha comprendido el planteamiento de Ortega y sus tensiones, el cual muchas veces debe ser entendido a pesar de y más allá de las contradicciones e insuficiencias del filósofo madrileño. Espinosa identificará también el error de Ortega, y propondrá -desde Ortega, pero más allá de sus recaídas en posturas típicas- una comprensión de la técnica en pie de igualdad a la capacidad proyectiva. 
Diríase que en el texto la técnica es sólo un medio subordinado e incluso un efecto (el sentido y la causa están fuera de ella, se dice), pero la impresión es engańosa: sí está en función de la vida y del fin que supone emplear esa energía autoconstructora, pero es así precisamente porque se trata de una condición de posibilidad esencial. Una vez más, y así arranca la cita, sin técnica no hay hombre, y aquélla no es instrumento de éste porque ambos empiezan a la par: son términos parejos, connaturales y estrictamente recíprocos. (Espinosa, 1998, p. 125)

\section{Propuesta de solución desde una radicación bio-antropológica}

Llegado a este punto, creo necesario exponer la que considero única salida a este embrollo, la cual pasa por reconducir la argumentación a su base biológica, base que es la del propio Ortega, por otra parte. La clave es entender que todo ser vivo lleva a cabo una mediación con su circunstancia, mediación que tiene una vertiente técnica y otra cognoscitivo-interpretativa. En la mayoría de animales, estas dos vertientes de su mediación se dan de manera conjunta y prácticamente indiscernible, pero en el ser humano (y otros animales complejos), estas dos vertientes sí aparecen hasta cierto punto distinguidas. Sin embargo, esta distinción no conlleva una separación real y efectiva, y se trata simplemente de distintas perspectivas sobre un fenómeno unitario: el de la mediación del organismo con su entorno. El organismo conductual se caracteriza, como su nombre indica, por conducirse y llevar a cabo acciones; y para ello debe proyectar su acción (interpretar su entorno y trazar un plan de actuación) y tener los medios técnicos efectivos para llevarla a cabo. Pero bien entendido que estos dos momentos no aluden a dos realidades separadas. Por tanto, el momento proyectivo y el momento técnico se dan en un circuito y mutua referencia continua, y es falso representárselos como dos momentos distintos y separados uno del otro. Pues carecería por completo de sentido que ningún organismo proyectara una acción que no puede efectivamente hacer, una acción para la cual no dispone de los medios, de la técnica necesaria para llevarla a cabo. El león que acecha a su presa no proyecta su acción de cazar contando con que podrá volar hacia su objetivo, sino que proyecta su acción de manera acorde a sus posibilidades técnicas efectivas, contando con su capacidad para acercarse sigilosamente a su presa mediante sus técnicas de camuflaje, contando con su capacidad para alcanzar a su presa mediante sus técnicas de persecución, y contando con su capacidad para matar a la presa con su técnica de degollamiento. 
Y, aun con todo, se entiende por qué Ortega -y con él casi toda la tradición filosófica- ha privilegiado la capacidad proyectiva (la capacidad interpretativa, la inteligencia), frente a la técnica. Pues a pesar de lo dicho en los párrafos anteriores, hay un ser que no podía volar, y sin embargo vuela; un ser que no disponía de la técnica para volar y sin embargo proyectó volar. Es en este sentido que antes veíamos a Ortega hablar del "deseo propiamente creador, el que postula lo inexistente, el que anticipa lo que aún es irreal” (V 576).

Pero esta misma descripción nos empieza a dar la clave: el hombre no podía volar, hubo un tiempo en que no podía, pero ahora sí puede. Los animales, por su parte, pueden lo mismo hoy que podían hace miles de años. He aquí una primera clave: el carácter acumulativo del hombre. Esta necesidad acumulativa exige una capacidad mediadora superior a la biológicamente dada. Una capacidad mediadora excesiva que -no podemos detenernos aquí- surge por las necesidades extra que requieren las crías humanas, para lo cual se abre una brecha en el mecanismo natural de satisfacción, que queda debilitado, favoreciendo la lógica del extra, del exceso, de la acumulación; la cual a su vez favorece el progresivo aumento de la capacidad mediadora (técnica e interpretativa). Sólo así se explica que el hombre pudiera llegar a hacer aquello que en principio no podía hacer.

Pues la cuestión es la siguiente: el progresivo distanciamiento respecto de la circunstancia en que se asienta la vida humana supone - y a la vez viene dado poruna hipertrofia de la capacidad técnica y de la capacidad interpretativa. Pero a raíz de este distanciamiento, de esta relativa ruptura respecto de la circunstancia, la propia capacidad mediadora y sus dos vertientes (la técnica y la proyección interpretativa) quedan desencajadas, dislocadas, desnaturalizadas. Y de este modo, la capacidad técnica y la capacidad interpretativa, al quedar relativamente desvinculadas de su referencia a la circunstancia con la que en principio estaban destinadas a mediar, quedan asimismo relativamente desvinculadas entre sí.

El extrañamiento general que supone el distanciamiento respecto de la circunstancia, comporta un extrañamiento particular de la propia mediación y de sus vertientes técnica e interpretativa. La mediación pierde o al menos debilita su relación con aquello respecto de lo que media (la circunstancia) y correlativamente la técnica y la interpretación pierden o ven debilitadas su mutua relación entre sí. Sólo en este contexto tiene sentido, o mejor dicho, puede explicarse que un ser proyecte acciones cuyos medios no están disponibles, como efectivamente sucede con el ser humano. Pero, y esto es clave, remarcando también que lo mismo sucede en sentido inverso: que por lo mismo este ser comienza también a crear técnicas sin una proyección o 
interpretación previa, como el propio Ortega descubrió en la técnica moderna. Así pues, nos encontramos con una explicación y justificación de la escisión desde la que la tradición filosófica ha pensado técnica e inteligencia; pero al mismo tiempo vemos que la preeminencia de la capacidad interpretativa sobre la capacidad técnica es, en última instancia, arbitraria, pues una y otra son dependientes e independientes en la misma medida. Su mutua dependencia es obvia y constitutiva desde el momento en que técnica e interpretación se entienden como dos vertientes, dos dimensiones, del fenómeno unitario que es la mediación de todo organismo conductual respecto de su entorno. Y su relativa y problemática independencia, tal y como se da en el hombre, es una independencia que se da en los dos sentidos: no sólo la capacidad proyectiva es relativamente independiente de la técnica, sino que la técnica es también relativamente independiente de la capacidad proyectiva (todo esto, se entiende, en el caso peculiar y anómalo del ser humano, pues en toda otra vida esta disonancia entre técnica y capacidad interpretativa simplemente no se da).

Por eso, a pesar de entender los motivos que han llevado a este error de comprender al proyecto como superior frente a la supuestamente secundaria técnica, no podemos dejar de declararlo como error y de proponer una alternativa que remarque su fondo de mutua dependencia, explicando su relativa independencia como algo que se da en ambos sentidos. Pues si nos situamos en el nivel explicativo de la dependencia entre ambas instancias, lo que diremos es que, si bien la técnica depende del proyecto, lo mismo sucede a la inversa, pues el proyecto depende de la técnica de la misma manera. Y si nos situamos en la perspectiva de su relativa y extraña independencia (algo que sólo sucede en la vida humana, y de forma relativa, como venimos remarcando), tendremos que decir, asimismo, que si el proyecto es en parte independiente de la técnica, lo mismo es la técnica también respecto del proyecto.

\section{Conclusiones: la tortuosa evolución intelectual de Ortega}

Como conclusión cabría decir que Ortega está siempre llegando o a punto de llegar a esta comprensión compleja de las relaciones entre proyecto y técnica, pero el inveterado prejuicio anti-técnico que entiende a la técnica como algo secundario hizo que Ortega no alcanzara plenamente una comprensión superior de este problema, pese a que el español constituya un ejemplo magnífico de anticipación en ambos sentidos - por su crítica al intelectualismo imperante en la tradición de la filosofía, y por su elevación del tema de la técnica al primer plano filosófico. Meditación de la técnica es, en este sentido, un texto especialmente problemático. Todo el recorrido de Ortega desde mediados de los 
años 20 apuntaba claramente a esta superación de todo reducto idealista y una comprensión antropo-metafísica en la que la técnica tendría un papel decisivo, no subordinado y secundario. $Y$ esto es lo que efectivamente sucede en la obra de Ortega; pero unido a ciertas confusiones y a cierta falta de radicalismo que no hacían justicia a la mejor parte de su filosofía.

Mi hipótesis es que, en el caso concreto de la técnica, las reflexiones de Ortega estaban hasta cierto punto enturbiadas por sus estudios histórico-sociales, principalmente España invertebrada y La rebelión de las masas, en los cuales la técnica siempre se le aparecía al filósofo español como manifestación de una deriva nihilista y desmoralizante. Desde esta perspectiva, son comprensibles las reticencias de Ortega a situar la técnica al mismo nivel que el proyecto de vida, pues, al hacer esto, su diagnóstico en los textos anteriores se resquebrajaría. Esto es lo que, de hecho, al menos parcialmente, sucedió; y es desde el reconocimiento de la insuficiencia de los análisis de España invertebrada y La rebelión de las masas de donde surge su gran proyecto filosófico de madurez. Pero, como decimos, en 1933, cuando prepara su curso ¿Qué es la técnica?, todavía no se ha desprendido totalmente de esta visión tópica de la técnica como elemento secundario dentro de la vida humana. Sus estudios en antropología y etnología no le habían dejado otro remedio que admitir sin paliativos que el hombre es un ser esencialmente técnico y que sin técnica no habría sido posible el hombre; pero aun concedido este punto capital, Ortega todavía mantiene en algunos textos, como sucede con ciertos pasajes de Meditación de la técnica, una cierta subordinación de la técnica frente al proyecto.

El problematismo de este tema y del propio texto de Meditación de la técnica se ven magnificados por una causa concreta: por el hecho de que Meditación de la técnica sea un texto escrito y reescrito a lo largo de los filosóficamente intensos años 30. Si analizamos minuciosamente los textos de esta época, podemos comprobar cómo incluso dentro de su madurez de los años 30, Ortega siguió profundizando y perfeccionando sus planteamientos. Esto es de suma importancia para entender Meditación de la técnica; pues si situamos la redacción de este texto en el año 1932-1933, en lugar de en 1939 cuando se publica, su relativa proximidad con La rebelión de las masas podría explicar la permanencia en este texto de cierto anti-tecnicismo. Esta puntualización nos permite, además, entender la tensión existente entre Meditación de la técnica y Ensimismamiento y alteración. Si la redacción de este segundo texto se sitúa en 1939 -o al menos unos años después de la redacción de Meditación de la técnicase entiende que Ortega hubiera podido madurar sus ideas y hubiera podido alcanzar una postura más compleja sobre varias cuestiones clave, incluida su 
filosofía de la técnica. Veamos, pues, lo que Ortega expone en Ensimismamiento $y$ alteración y cómo estas ideas entran en colisión con los pasajes antes citados de Meditación de la técnica.

En las primeras páginas de Ensimismamiento y alteración Ortega traza una comparación entre el hombre y el animal, a raíz de la cual descubre en el hombre dos diferencias fundamentales: su técnica y su ensimismamiento. Pero, y esto es importante, en el texto de 1939, a diferencia del de 1933, uno y otro principio se dan de manera simultánea, ya no hay prioridad lógica ni cronológica del ensimismamiento frente a la técnica ni de la técnica frente al ensimismamiento:

Por eso, si el hombre goza de ese privilegio de libertarse transitoriamente de las cosas, y poder entrar y descansar en sí mismo, es porque con su esfuerzo, su trabajo y sus ideas ha logrado reobrar sobre las cosas, transformarlas y crear en su derredor un margen de seguridad siempre limitado, pero siempre o casi siempre en aumento. Esta creación específicamente humana es la técnica. Gracias a ella, y en la medida de su progreso, el hombre puede ensimismarse. Pero también, viceversa, el hombre es técnico, es capaz de modificar su contorno en el sentido de su conveniencia, porque aprovechó todo respiro que las cosas le dejaban para ensimismarse, para entrar dentro de sí y forjarse ideas sobre ese mundo, sobre esas cosas y su relación con ellas, para fraguarse un plan de ataque a las circunstancias. En suma, para construirse un mundo interior. De este mundo interior emerge y vuelve al de fuera. Pero vuelve en calidad de protagonista, vuelve con un sí mismo que antes no tenía -con su plan de campaña-, no para dejarse dominar por las cosas, sino para gobernarlas él, para imponerles su voluntad y su designio, para realizar en ese mundo de fuera sus ideas, para modelar el planeta según sus las preferencias de su intimidad. (V 537)

Ensimismamiento y técnica son dos principios co-originarios. El hombre puede ensimismarse por la holgura material que la técnica hace posible; pero al mismo tiempo, el hombre es técnico por su voluntad de resistir al contorno, de no responder automáticamente como el animal alterado, sino de fraguar su plan de acción desde su ensimismamiento. Desde este planteamiento, carece de sentido decir que el ensimismamiento y los proyectos que de él emanan dictaminan unilateralmente la técnica. El ensimismamiento depende de la técnica de la misma manera que la técnica depende del ensimismamiento. La mutua dependencia entre ambos hace que sea imposible representarse a uno sin el otro, lo cual lleva a la conclusión de que ambos se dieron en el hombre primitivo -y en el actual, aunque no se vea tan claro- de manera co-originaria, y que ambos 
merecen un mismo estatus y reconocimiento dentro de la estructura de la vida humana. Como resumirá L. Espinosa: "No hay un principio absoluto, sea lógico o cronológico, sino esa recursividad constante entre técnica y ensimismamiento" (1998, p. 124). En Ensimismamiento y alteración Ortega expone de manera muy clara la dinámica que tiene lugar entre técnica y ensimismamiento:

Pero, aun instantáneo y tosco, ese primitivo ensimismamiento va a separar radicalmente la vida humana de la animal. Porque ahora el hombre, este hombre primigenio, va a sumergirse de nuevo entre las cosas del mundo, resistiéndolas, sin entregarse del todo a ellas. Lleva un plan contra ellas, un proyecto de trato con ellas, de manipulación de sus formas que produce una mínima transformación de su derredor, la suficiente para que le opriman un poco menos y, en consecuencia, le permitan más frecuentes y holgados ensimismamientos... y así sucesivamente. (V 539)

El ensimismamiento permite técnicas que a su vez permiten mejores y mayores ensimismamientos; y viceversa: la técnica permite ensimismamientos que a su vez permiten mejores y mayores técnicas. Esta intimísima imbricación y mutua dependencia hacen sospechar lo que ya hemos apuntado: que técnica y ensimismamiento son, en realidad, dos caras, dos aspectos, de un mismo fenómeno unitario. Siguiendo con el texto de Ensimismamiento y alteración, Ortega expondrá la estructura de la vida humana en un sentido histórico en términos similares a los que hemos venido utilizando:

Son pues, tres momentos diferentes, que cíclicamente se repiten a lo largo de la historia humana en formas cada vez más complejas y densas: $1^{\circ}$, el hombre se siente perdido, náufrago en las cosas, es la alteración; $2^{\circ}$, el hombre, con un enérgico esfuerzo, se retira a su intimidad, para formarse ideas sobre las cosas y su posible dominación; es el ensimismamiento, la vita contemplativa, que decían los romanos, el theoretikós bios, de los griegos, la theoria; $3^{\circ}$, el hombre vuelve a sumergirse en el mundo, para actuar en él conforme a un plan preconcebido; es la acción, la vita activa, la praxis. (V 539)

Lo decisivo de este texto es la distinción que Ortega establece entre alteración y acción, o, como dice recuperando el término griego, praxis. Aunque volveremos sobre este tema concreto un poco después, podemos aquí citar un texto de Ensimismamiento y alteración, que será repetido en El hombre y la gente (cf. X 151) y que deja muy clara su posición: 
... acción no es cualquier andar a golpes con las cosas en torno, o con los otros hombres: eso es lo infrahumano, eso es la alteración. La acción es actuar sobre el contorno de las cosas materiales o de los otros hombres conforme a un plan preconcebido en una previa contemplación o pensamiento. No hay, pues, acción auténtica si no hay pensamiento, y no hay auténtico pensamiento si éste no va debidamente referido a la acción y virilizado por su relación con ésta. (V 543)

Tras esta declaración de intenciones Ortega lanzará una dura crítica al conjunto de la tradición filosófica por su intelectualismo, por su "idolatría de la inteligencia, que aísla al pensamiento de su encaje, de su función en la economía general de la vida humana" (V 544). Este gran problema de la filosofía, que se remonta a sus orígenes griegos (cf. V 544), consiste en una "divinización de la inteligencia" (V 544), que según Ortega también profesaban sus maestros alemanes (cf. V 544). Ortega se rebela contra esto, hasta el punto de afirmar que "toda mi obra, desde sus primeros balbuceos, ha sido una lucha contra esa actitud, que hace muchos años llamé beatería de la cultura" (V 544-545). Ortega denunciará una inversión de "la relación efectiva entre vida y cultura, entre acción y contemplación” (V 545), error en el que había caído no sólo la tradición filosófica sino también el pensamiento vigente de su época. Ambas instancias, contemplación y acción, teoría y práctica, se dan en continuidad y se implican mutuamente: "Según esto, no puede hablarse de acción sino en la medida en que va a estar regida por una previa contemplación; y viceversa, el ensimismamiento no es sino proyectar la acción futura" (V 539).

¿Por qué Ortega, teniendo tan claro este punto, tanto que entiende la crítica al intelectualismo como lo definitorio de su tarea filosófica, por qué, repito, recayó en un cierto intelectualismo y privilegio de lo intelectual? La respuesta, claro está, no podrá ser sencilla ni definitiva. En este artículo no podemos decir la última palabra sobre esta cuestión, pero sí cabe apuntar a la compleja evolución intelectual de Ortega, en la que no faltarán las oscilaciones y los altibajos, pero que cada vez se acerca más a una comprensión compleja y problemática -y por tanto más cercana a la realidad- de las relaciones entre teoría y práctica, y por extensión a las relaciones entre proyectividad y técnica. 


\section{Bibliografía}

Cerezo Galán, Pedro (1984). La voluntad de aventura. Aproximamiento critico al pensamiento de Ortega y Gasset. Barcelona: Ariel.

Diéguez lucena, Antonio y Zamora Bonilla, Javier (2015). “Introducción”. En Ortega y Gasset, José. Meditación de la técnica; Ensimismamiento y alteración. Madrid: Biblioteca Nueva, pp. 9-38.

Dust, Patrick H. (1993). "Amando lo artificial: Ortega y Gasset y nuestra relación con la técnica hoy”. Isegoría. Revista de Filosofía Moral y Politica, no 7, pp. 123-134.

Ellacuría Beascoechea, Ignacio (1996). Técnica y vida humana en Ortega y Gasset: Estudio de "Meditación de la técnica». Escritos filosóficos, vol. I, San Salvador: UCA, 1996, pp. 415-518.

Espinosa Rubio, Luciano (1998). "La técnica como radical ecología humana”. El hombre y su medio. Perspectivas ecológicas desde Ortega y Gasset, Paredes Martín, María del Carmen (Ed.) Salamanca: departamento de filosofía y lógica, pp. 119142.

Esquirol i Calaf, Josep María (2011). Los filósofos contemporáneos y la técnica: de Ortega a Sloterdijk. Barcelona: Gedisa.

GonzÁlez Quirós, José LuIs (2013). “El centauro Quirón”. Revista Internacional de Tecnología, Conocimiento y Sociedad (Vol. 2, No 1), Universidad Carlos III de Madrid, pp. 99-109.

Ortega y Gasset, José (2004-2010). Obras completas. Tomos I-X. Madrid: Taurus.

Quintanilla Navarro, Ignacio (1999). Téchne. Filosofía para ingenieros. Madrid: Noesis.

Recibido: $13 / 11 / 2017$

Aceptado: 4/12/2017

\section{(9) $\mathbb{Q 0 0}$}

ENDOXA está bajo una licencia de Creative Commons Reconocimiento-NoComercial-SinObraDerivada 4.0 Internacional 